Int. J. Dev. Biol. 54: 925-929 (2010)

doi: $10.1387 /$ ijdb.092933jc

\title{
Molecular cloning of chicken Cecr2 and its expression during chicken embryo development
}

\author{
JINGCHEN CHEN 1,2,4, GABRIELA MOROSAN-PUOPOLO ${ }^{1,3}$, FANGPING DAI ${ }^{1}$, \\ JIANLIN WANG ${ }^{2}$ and BEATE BRAND-SABERI*1,4 \\ ${ }^{1}$ Institute of Anatomy and Cell Biology, Department of Molecular Embryology, University of Freiburg, Germany, \\ ${ }^{2}$ School of Life Sciences, Lanzhou University, P. R. China, ${ }^{3}$ Institute of Biology I, University of Freiburg and \\ ${ }^{4}$ Institute of Anatomy, Department of Anatomy and Molecular Embryology, Ruhr-University of Bochum, Germany
}

\begin{abstract}
Cecr2 is a transcription factor involved in neurulation and chromatin remodeling. In the present study, the full length of the coding sequence of the chicken orthologue Cecr2 was obtained by RT-PCR. Sequence analysis and alignment showed that it contained an AT hook, as well as a bromodomain which was highly conserved among different species, consistent with its role in chromatin remodeling. The expression pattern of chicken Cecr 2 was subsequently investigated during the development of the chicken embryo by in situ hybridization. In addition to its predominant expression in neural tissues during neurulation, Cecr2 was also found to be expressed in the developing somites and in the intermediate zone of the spinal cord, suggesting that it may play a role in somite and neuronal development.
\end{abstract}

KEY WORDS: Cecr2, myotome, spinal cord, neurulation, chicken embryo

\section{Introduction}

Cecr2 was first identified in the region q11.2 of human chromosome 22 (Footz et al., 2001). The full length of the coding region is $4392 \mathrm{bp}$, containing an AT hook and a bromodomain that are present in many chromatin remodeling proteins. The protein product CECR2, together with SNF2L, is involved in chromatin remodeling in vitro (Banting et al., 2005). In the mouse, Cecr2 transcripts are mainly expressed in neural tissues such as neural folds, recently closed neural tube and limb mesenchyme. Mutation of Cecr2 leads to a high rate of exencephaly and prenatal death (Banting et al., 2005), indicating that Cecr2 is involved in neurulation.

In the chicken, three ESTs of Cecr2 are reported in BBSRC ChickEST Database (http://www.chick.manchester.ac.uk/). In our study, we cloned the full length of the coding sequence of chicken Cecr2and investigated its expression pattern during the development of the chicken embryo. In addition to the expression pattern which resembles that of the neurulation stage in the mouse embryo, the signal present in the somite and the spinal cord argued for potential functions of Cecr2 during embryo development, in addition to its roles reported.

\section{Results}

\section{Molecular cloning and sequence analysis}

The coding sequence of chicken Cecr2has a length of $4422 \mathrm{bp}$ (Accession No: EU850803), encoding a putative protein of 1473 amino acids (Fig. 1). Motif discovery with Pfam revealed that the protein contains a bromodomain and an AT hook (Fig. 1). Sequence alignments showed these two motifs are highly conserved among human, mouse, chicken and zebrafish Cecr2 (Fig. 1).

\section{Expression of Cecr2 during chicken embryo development Neural tissues}

Cecr2transcripts were present in the neural folds and newly formed neural tube from $\mathrm{HH}$ stage 8 onwards (Fig. $2 \mathrm{~A}, \mathrm{~B}, \mathrm{D}, \mathrm{E}$ ). As the neural tube matured and partitioned rostrocaudally, the expression of Cecr2was gradually restricted to the dorsal region of the neural tube and brain vesicles (Fig. 2 C,F,G,H). After HH stage 19 , the signal extended towards the ventral side of the intermedi-

Abbreviations used in this paper: Cecr2, cat eye syndrome chromosome region, candidate 2; DML, dorsal medial lip; DRG, dorsal root ganglia; VLL, ventral lateral lip.

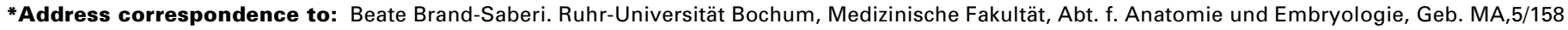
D44780 Bochum, Germany. Fax: + 49-234-321-4474.

e-mail: Beate.Brand-Saberi@ruhr-uni-bochum.de - web: http://portal.uni-freiburg.de/anatomie2/staff/brand-saberi
}

Accepted: 22 September 2009. Final author corrected PDF published online: 8 February 2010. 


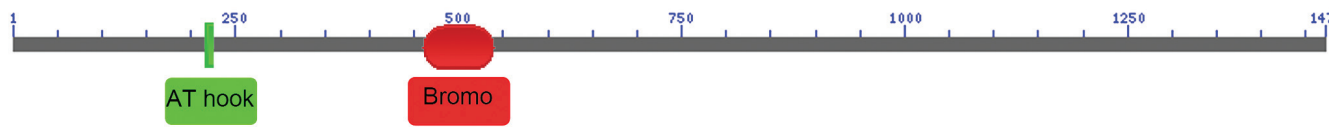

hCECR2 gi|148612882|ref|NP 113 mCECR2_gi|189458854|ref|NP 001 CCECR2_gi|l 194395392 | gb | ACF 6023 zCECR2_gi|l89537445 | ref|XP_001

hCECR2 gi|148612882|ref|NP 113 mCECR2_gi|l89458854|reflNP_001 cCECR2_gi|194395392 | gb |ACF 6023 zCECR2_gi|189537445|ref|XP_001

hCECR2_gi|148612882|ref INP_113 mCECR2 gi|189458854|ref|NP 001 CCECR2_gi|194395392 | gb|ACF 6023 zCECR2_gi|189537445|ref|XP 001

Fig. 1. Cecr2 sequence analysis and alignments. The approximate positions of AT hook and bromodomain in the protein are marked on the scaled line representing the full length of cCecr2. In sequence alignment, green box outlines the AT hook. Red line delimits the bromodomain.

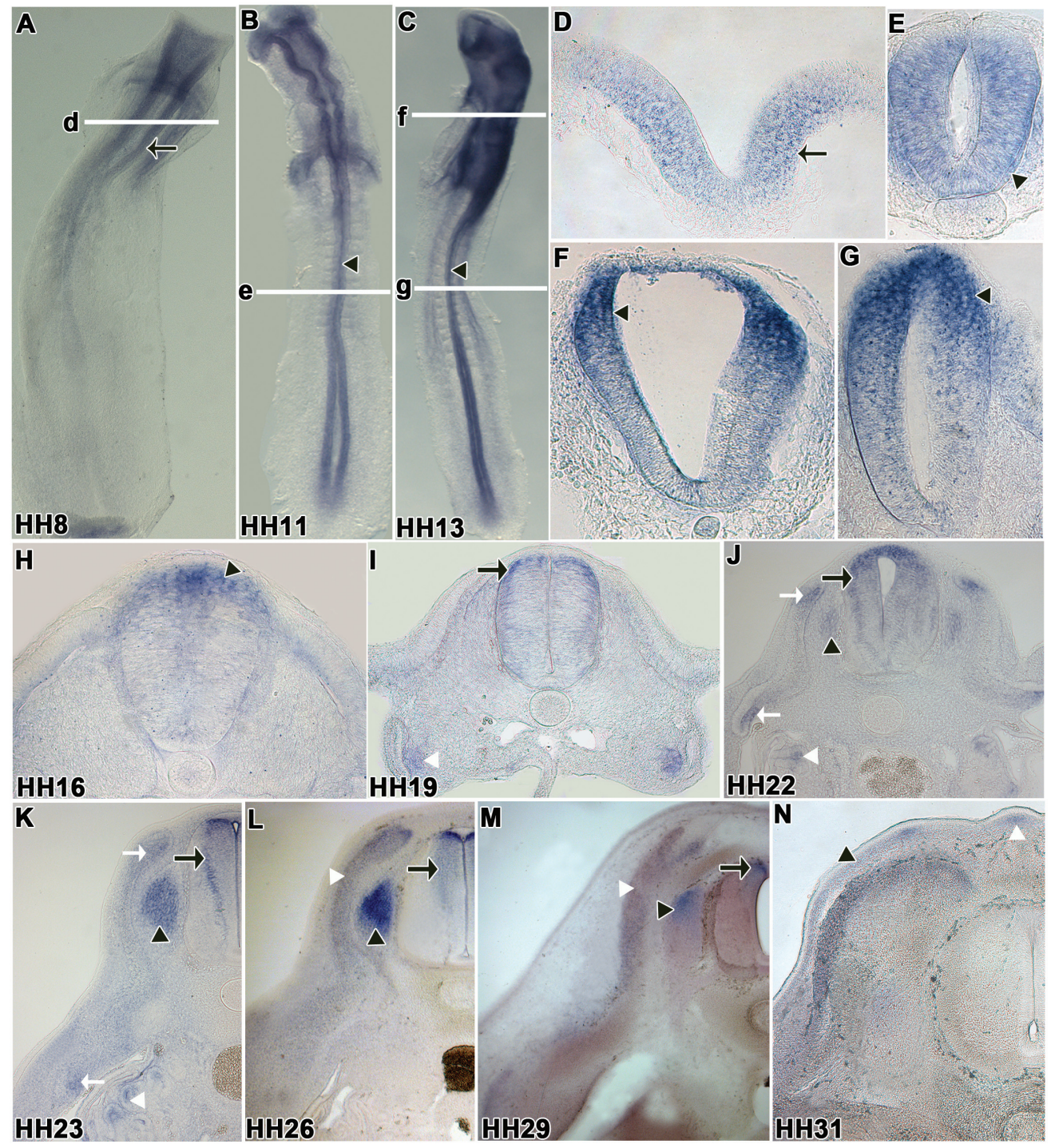

ate layer of the spinal cord and was maintained there (Fig. $2 \mathrm{I}, \mathrm{J}, \mathrm{K}$ ). After $\mathrm{HH}$ stage 26, the expression in the intermediate layer declined (Fig. 2 L,M) until completely vanishing at $\mathrm{HH}$ stage 31 (Fig. $2 \mathrm{~N}$ ). Notably, Cecr2 was expressed in the dorsal root ganglia (DRG) from $\mathrm{HH}$ stage 22 to 29 as well (Fig. 2 $J, K, L, M)$.

\section{Somites and limb buds}

At HH stage 16, the expression of Cecr2was observed in the mesenchyme of the lateral plate-derived mesoderm at limb level (Fig. $3 \mathrm{~A}, \mathrm{~B})$. The expression domain in the mesenchyme increased as the limb bud grew (Fig. 3D). From HH stage 18, Cecr2 appeared at the cranial and caudal border of rostral somites (Fig. 3 C,D). At around $\mathrm{HH}$ stage 22 or 23 , the dorsal medial and ventral lateral regions of the somites were positive for Cecr2expression (Fig. 3E,F). Sections revealed that the expression was located in the sub-lips of the dorsal medial lip (DML) and ventral lateral lip (VLL) (Fig. $2 \mathrm{~J}, \mathrm{~K}$ ). During these stages, the signal in limb buds was gradually restricted to the distal mesenchyme (Fig. 3 $\mathrm{E}, \mathrm{F})$. It completely vanished in the mesenchyme, but was present in the dorsal and ventral myogenic zones after HH stage 27(Fig. 3K), while in the somite, it was further

Fig. 2. Cecr2 expression in neural tissues and somites. (A,B,D,E) $E x$ pression is present in neural folds (black arrows) and newly formed neural tube (black arrowheads) from HH stage 8 to 11. (C, $\mathbf{F}, \mathbf{G}, \mathbf{H})$ The signal is restricted to the dorsal region of the neural tube and brain vesicles from HH stage 13 to 16 (black arrowheads). (H-N) The expression in the intermediate layer of the spinal cord (black arrows) and DRG (black arrowheads) is dynamic, appearing from HH stage 19 and disappearing at $\mathrm{HH}$ stage 31. In somites, Cecr2 is expressed in sub-lips (white arrows in $J, K)$ of $D M L$ and $V L L$, mesenchyme (white arrowheads in $\mathrm{L}, \mathrm{M}$ ) originating from dermomyotome, epidermis (black arrowhead in N) and feather buds (white arrowhead in N). The signal is also positive in the mesonephric duct (white arrowheads in I, J,K). 


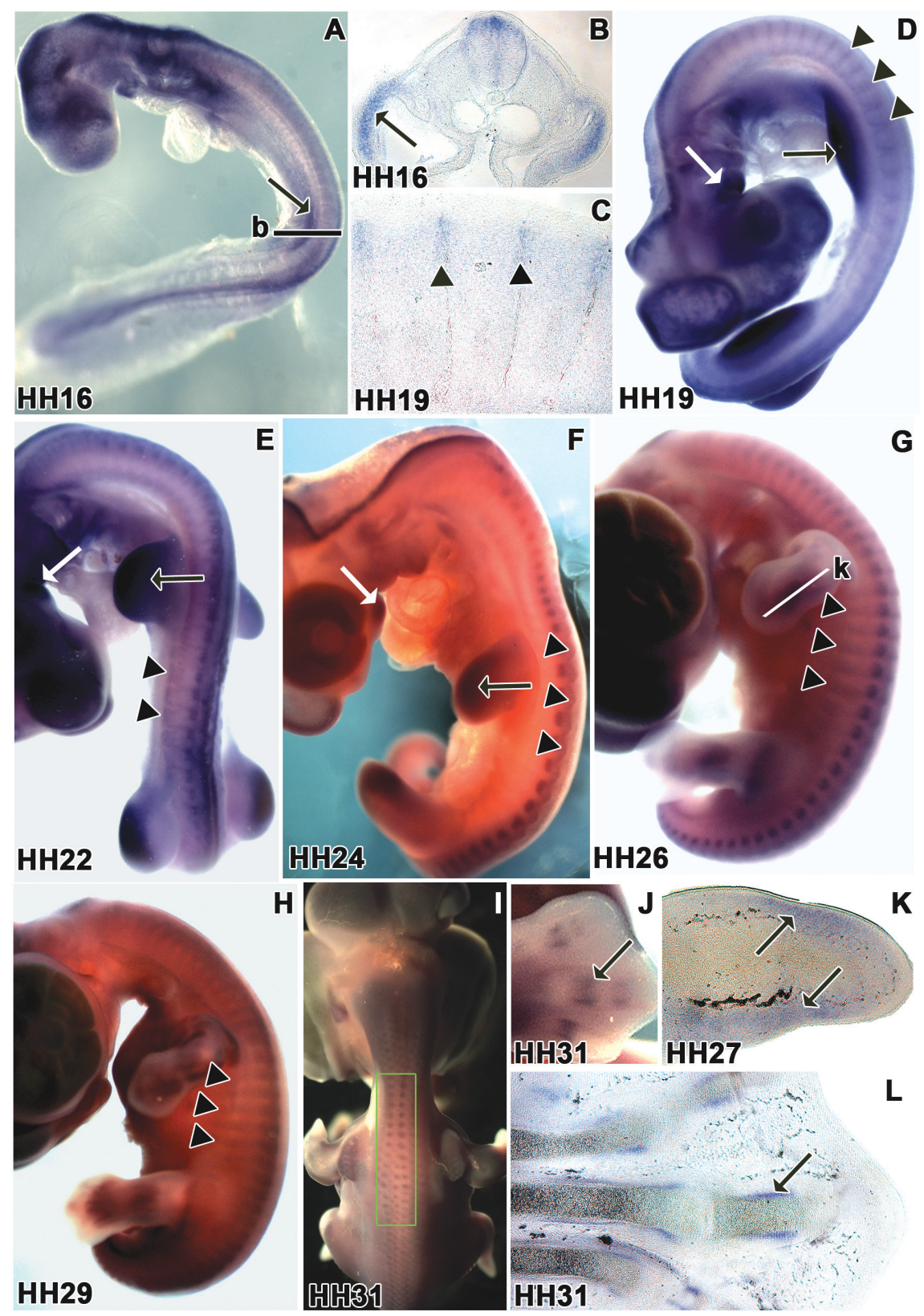

Fig. 3. Expression of Cecr2in limb buds and somites. In limb buds, Cecr2 transcripts are strongly expressed in the mesenchyme (black arrows in $\mathbf{A}, \mathbf{B}, \mathbf{D}$ ), and gradually restricted to the distal region (black arrows in $\mathbf{E}, \mathbf{F}$ ). They are present in the dorsal and ventral myogenic zone black arrows in $\mathbf{K}$, which comes from cross section of $\mathrm{G}$ at forelimb level) and perichodrium (black arrows in $\mathbf{J}, \mathbf{L}$ ) of developing digits. (D-H) Overview of Cecr2 expression in somites from the whole mount in situ hybridization, which is further revealed in detail by sections illustrated in Fig. 2. In somites, Cecr2 is initially expressed in the rostral and caudal borders of somites (black arrowheads in C,D. C shows sagittal section of $D)$. The transcripts later are present in the ventral lateral region (black arrowheads in $\mathbf{E}$ ) and dorsal medial region

G (black arrowheads in $\mathbf{F}$ ) of the somites. The expression becomes moderately positive through the somites (black arrowheads in $\mathbf{G}, \mathbf{H}$ ). The expression is also positive in pharyngeal arches (white arrows in $\mathbf{D}, \mathbf{E}, \mathbf{F}$ ). At HH stage 31, the signal is present in feather buds (green frame in $\mathbf{I}$ ).

Frekwas expressed in the ventral region of the myotome (Fig. 4 e,f). From $\mathrm{HH}$ stage 23 to $\mathrm{HH}$ stage 25, Cecr2 expression was restricted to the dorsal medial and ventral lateral regions of somites (Fig. 4 C,D). Sections revealed that the expression was located in the sub-lips of DML and VLL (Fig. 4 c,d). In contrast, Frekextended through the whole somite (Fig. $4 \mathrm{G}, \mathrm{H}$ ). Sections showed that it was expressed in the whole myotome (Fig. $4 \mathrm{~g}, \mathrm{~h}$ ).

\section{Discussion}

\section{Roles of conserved domains in Cecr2}

The bromodomain can interact specifically with acetylated lysine (Haynes etal., 1992), and may be involved in protein-protein interactions as well as the assembly or activity of multicomponent complexes involved in transcriptional activation (Tamkun, 1995). It is 110 amino acid long and found in many chromatin-associated proteins. The so-called AT hook is a DNA binding motif with a preference for $A / T$ rich regions. It is suggested that proteins with AT hook could function in nucleosome phasing (Reeves and Nissen, 1990). Both of the two motifs are characteristic of many chromatin remodeling proteins (Flaus and Owen-Hughes, 2001). In vitro study reveals that $\mathrm{Cecr} 2$ is indeed involved in chromatin remodeling (Banting et al., 2005). The high conservancy of these two motifs among different species suggests that Cecr2 may function in the same conserved chromatin-remodeling way among different organisms.

\section{Possible roles of Cecr2 during embryo development Myotome development}

Myotome development is a multi-step process that comprises four waves of cell recruitment. The first wave arises from the dorsomedial wall of the epithelial somite where cells spread underneath the dermomyotome as a scaffold for the second

\section{of somites at interlimb level. Sections revealed that Cecr2 occupied the dorsal region of the myotome (Fig. 4 a,b), while \\ Comparisons of expression pattern between Cecr2 and Frek in somites \\ From HH stage 19 to $\mathrm{HH}$ stage 21, both Cecr2 (Fig. $4 \mathrm{~A}, \mathrm{~B}$ ) and Frek(Fig. 4 E,F) appeared at the rostral and caudal borders}


wave of postmitotic cells which arise from all four edges of the dermomyotome (Gros etal., 2004; Kahane etal., 1998a; Kahane et al., 1998b). The third wave cells enter from the rostral and caudal lips of the dermomyotome. They are mitotically active, and express Frek (Kahane et al., 2001). Finally, cells delaminate from the center of the dermomyotome to enter the myotome, making up the fourth wave of mitotically active, Frekexpressing muscle precursors (Gros et al., 2005).

Of the four waves that contribute to myotome formation, two populations of cells have origins from rostral and caudal lips of the dermomyotome. One population belongs to the third wave of which cells are Frekpositive (Kahane et al., 2001). The other one belongs to the second wave of which cells arise from four

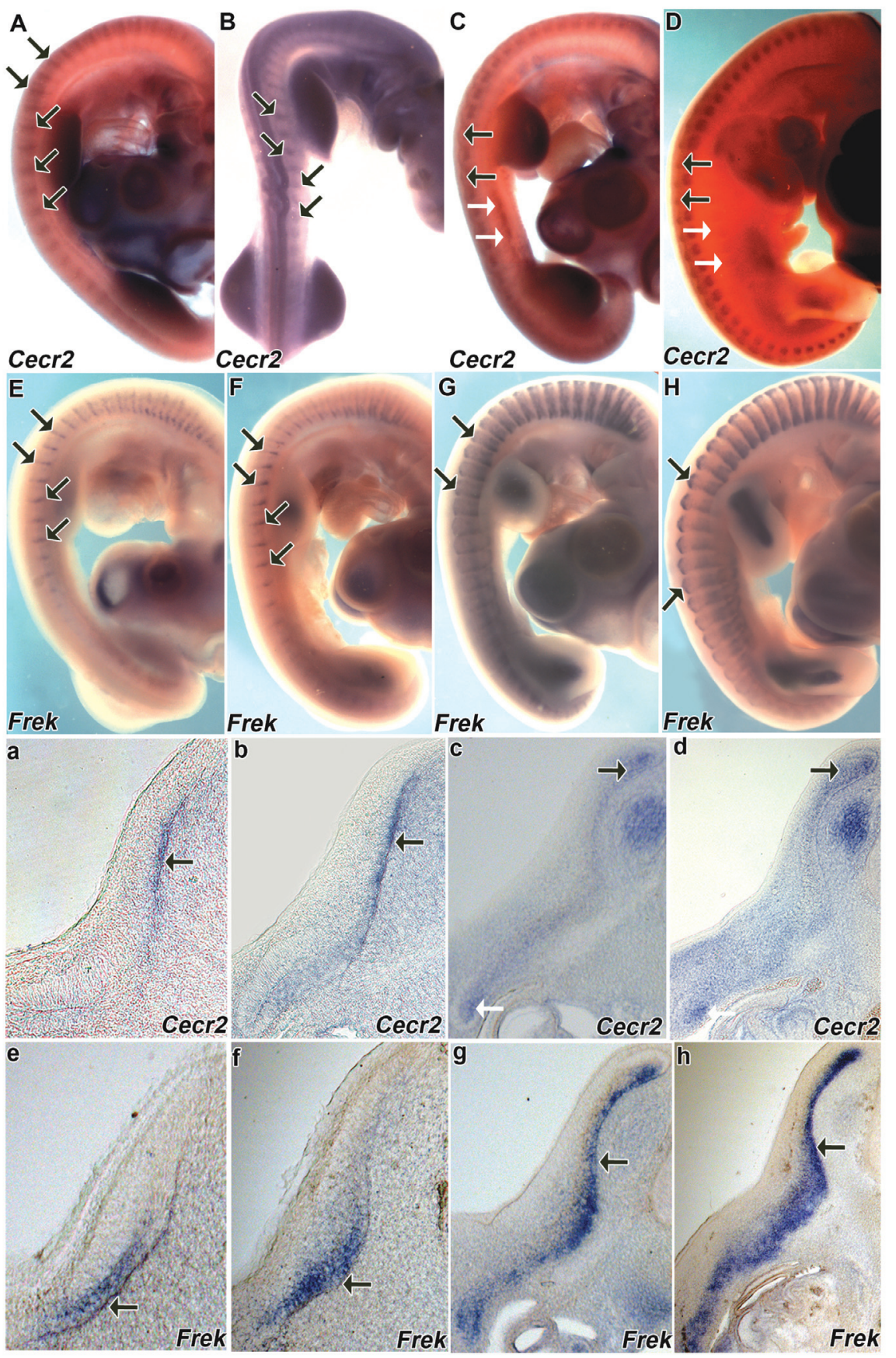

borders of the dermomyotome (Gros et al., 2004; Kahane et al., 1998a). In our observation, though Cecr2 is expressed in the rostral and caudal borders of the somites, it has a distinctly different expression pattern from Frek. In brief, Cecr2 expression is restricted to the four borders of the dermomyotome, while Frekextends through the whole myotome from the rostral and caudal lips. The disparity distinguishes the Cecr2-expressing cells from the Frek-positive cells, thus ruling out the possibility of Cecr2expressed in cells of the third wave. Additionally, Cecr2 expression is concomitant with the initial phase of cell dynamics of the second wave. Accordingly, we suggest that Cecr2 is expressed in subpopulation of the second-wave cells during myotome development, probably the ones arising from the four edges which correlate with Cecr2 expression.

\section{Neural development}

A study in the mouse shows that Cecr2 is expressed in the neural folds and the recently closed neural tube and that mutation of mouse Cecr2leads to exencephaly. These results indicate that Cecr2is involved in neurulation (Banting et al., 2005). In support, there is a similar expression pattern during neurulation in the chick embryo. After neurulation, the Cecr2 expression domain is gradually restricted to the dorsal neural tube. During this period, the ventral signal Sonic hedgehog $(\mathrm{SHH})$ and the dorsal signal of Tgf- $\beta$ proteins are shaping the dorsal-ventral polarity of the neural tube (Wilson and Maden, 2005). The recession of Cecr2 expression may be related to such signaling networks. Continuous expression of Cecr2 is also observed in the intermediate layer of the spinal cord and DRG, which consist of postmitotic neuronal cells imminent to further differentiate (Lee et al., 1995; Roztocil et al., 1997). Persistent expression of Cecr2in these two regions suggests that Cecr2 may function during neuronal development.

Fig. 4. Expression of Cecr2 and Frek in somites. $(\mathbf{A}, \mathbf{B})$ Cecr2 is expressed in the rostral and caudal borders of somites (black arrows) at HH stage 19 and $H H$ stage 21. $(\mathbf{a}, \mathbf{b})$ Cross sections from $(A, B)$ show Cecr2 expression in the dorsal region of the cranial and caudal borders of the somite at interlimb level (black arrows). (C,D) The expression of Cecr2 is moderately positive in the dorsal medial region (black arrows) and ventral lateral region (white arrows) of somites at $\mathrm{HH}$ stage 23 and HH stage 25. Sections reveal that the expression is located in the sub-lips (black and white arrows in $\mathbf{c , d}$ ) of DML and VLL. (E,F) Expression of Frek in the rostral and caudal borders (black arrows) of somites at $\mathrm{HH}$ stage 19 and HH stage 21. (e,f) Cross sections from E, Fshow Frek expression in the ventral region of the cranial and caudal borders of the somite at interlimb level. $(\mathbf{G}, \mathbf{H})$ The expression of Frek extends through somites. (g,h) Cross sections from $G, H$ indicate that Frek transcripts are positive through the whole myotome (black arrows). 
TABLE 1

\section{PRIMERS FOR RT-PCR OF CHICKEN CECR2}

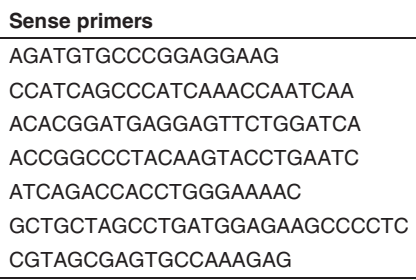

\section{Limb development}

Cecr2 transcripts persist in the mesenchyme of the limb bud from $\mathrm{HH}$ stage 16 to 21, but gradually diminish along the proximaldistal (P-D) axis afterwards. Fgf10 has the same expression pattern in the limb bud. It interacts with Fgf8 from the apical ectodermal ridge (AER) to maintain the outgrowth of the limb bud (Ohuchi et al., 1997). Possibly, Cecr2may correlate with Fgf10or its signaling cascade during early limb development. Besides, presence of Cecr2 in the perichondrium of developing digits implies its participation in the chondrogenic processes as well.

\section{Materials and Methods}

\section{$R T-P C R$ and sequence analysis}

Total chicken mRNA was extracted with Trizol reagent (Invitrogen). Seven pairs of primers were used for RT-PCR (Table 1). The amplified fragments were purified from $1 \%$ agarose gel. cDNA fragments of interest were cloned into the pDrive vector (Qiagen) and then sequenced. Sequence analysis was performed with Pfam (Finn et al., 2006). Sequence alignments were made with clustalW2 provided in EBI (http:// www.ebi.ac.uk/Tools/clustalw2/).

\section{Probe preparation}

A 967 bp cDNA fragment of chicken Cecr2 was obtained by RT-PCR. The fragment was ligated into the pDrive vector. The pDrive-Cecr2 plasmid was linearised with HindIII, and the antisense probe was synthesized with T7 RNA polymerase. The sense probe as control was synthesized with SP6 RNA polymerase after linearising the plasmid with $\mathrm{BamHI}$. Frek probe was prepared from plasmid presented by Marcelle and colleagues (Marcelle et al., 1994).

\section{In situ hybridization and sectioning}

Fertilized chicken eggs obtained from a local breeder were incubated at $38^{\circ} \mathrm{C}, 80 \%$ humidity. Embryos were staged according to Hamburger and Hamilton (1951), sacrificed and fixed in 4\% PFA/PBT. Whole mount in situ hybridization was performed as described (Nieto, 1996). Embryos were sectioned at a thickness of $40-60 \mu \mathrm{m}$ using a Leica vibratome. Sections were photographed with Leica DFC320 digital camera mounted to the microscope Axioscope 20 from Zeiss.

\section{Acknowledgements}

The authors appreciate Ulrike Pein and Susanna Glaser for theirtechnical assistances and would like to thank Wanghong Zhao, Rizwan Rehimi, Nargis Khalida and Bea Redinger for their advice. The study was funded by the Chinese Scholarship Council (CSC L 07024) and Grako 1104.

\section{References}

BANTING, G.S., BARAK, O., AMES, T.M., BURNHAM, A.C., KARDEL, M.D. COOCH, N.S., DAVIDSON, C.E., GODBOUT, R., MCDERMID, H.E. and SHIEKHATTAR, R. (2005). CECR2, a protein involved in neurulation, forms a novel chromatin remodeling complex with SNF2L. Hum Mol Genet 14:513-524.

FINN, R.D., MISTRY, J., SCHUSTER-BOCKLER, B., GRIFFITHS-JONES, S., HOLLICH, V., LASSMANN, T., MOXON, S., MARSHALL, M., KHANNA, A., DURBIN, R. et al. (2006). Pfam: clans, web tools and services. Nucleic Acids Res 34: D247-D251.

FLAUS, A. and OWEN-HUGHES, T. (2001). Mechanisms for ATP-dependent chromatin remodelling. Curr Opin Genet Dev 11: 148-154.

FOOTZ, T.K., BRINKMAN-MILLS, P., BANTING, G.S., MAIER, S.A., RIAZI, M.A., BRIDGLAND, L., HU, S., BIRREN, B., MINOSHIMA, S., SHIMIZU, N. et al. (2001). Analysis of the cat eye syndrome critical region in humans and the region of conserved synteny in mice: a search for candidate genes at or near the human chromosome 22 pericentromere. Genome Res 11: 1053-1070.

GROS, J., MANCEAU, M., THOME, V. and MARCELLE, C. (2005). A common somitic origin for embryonic muscle progenitors and satellite cells. Nature 435: 954-958.

GROS, J., SCAAL, M. and MARCELLE, C. (2004). A two-step mechanism for myotome formation in chick. Dev Cel/6: 875-882.

HAYNES, S.R., DOLLARD, C., WINSTON, F., BECK, S., TROWSDALE, J. and DAWID, I.B. (1992). The bromodomain: a conserved sequence found in human, Drosophila and yeast proteins. Nucleic Acids Res 20: 2603.

KAHANE, N., CINNAMON, Y., BACHELET, I. and KALCHEIM, C. (2001). The third wave of myotome colonization by mitotically competent progenitors: regulating the balance between differentiation and proliferation during muscle development. Development 128: 2187-2198.

KAHANE, N., CINNAMON, Y. and KALCHEIM, C. (1998a). The cellular mechanism by which the dermomyotome contributes to the second wave of myotome development. Development 125: 4259-4271.

KAHANE, N., CINNAMON, Y. and KALCHEIM, C. (1998b). The origin and fate of pioneer myotomal cells in the avian embryo. Mech Dev 74: 59-73.

LEE, J.E., HOLLENBERG, S.M., SNIDER, L., TURNER, D.L., LIPNICK, N. and WEINTRAUB, H. (1995). Conversion of Xenopus ectoderm into neurons by NeuroD, a basic helix-loop-helix protein. Science 268: 836-844.

MARCELLE, C., EICHMANN, A., HALEVY, O., BREANT, C. and LE DOUARIN, N.M. (1994). Distinct developmental expression of a new avian fibroblast growth factor receptor. Development 120: 683-694.

NIETO, M., PATEL K, WILKINSON DG. (1996). In situ hybridization analysis of chick embryos in whole mount and tissue sections. Methods Cel/ Bio/51:219235.

OHUCHI, H., NAKAGAWA, T., YAMAMOTO, A., ARAGA, A., OHATA, T., ISHIMARU, Y., YOSHIOKA, H., KUWANA, T., NOHNO, T., YAMASAKI, M. etal. (1997). The mesenchymal factor, FGF10, initiates and maintains the outgrowth of the chick limb bud through interaction with FGF8, an apical ectodermal factor. Development 124: 2235-2244.

REEVES, R. and NISSEN, M.S. (1990). The A.T-DNA-binding domain of mammalian high mobility group I chromosomal proteins. A novel peptide motif for recognizing DNA structure. J Bio/ Chem 265: 8573-8582.

ROZTOCIL, T., MATTER-SADZINSKI, L., ALLIOD, C., BALLIVET, M. and MATTER, J.M. (1997). NeuroM, a neural helix-loop-helix transcription factor, defines a new transition stage in neurogenesis. Development 124: 3263-3272.

TAMKUN, J.W. (1995). The role of brahma and related proteins in transcription and development. Curr Opin Genet Dev 5: 473-477.

WILSON, L. and MADEN, M. (2005). The mechanisms of dorsoventral patterning in the vertebrate neural tube. Dev Bio/282: 1-13. 


\section{Further Related Reading, published previously in the Int. J. Dev. Biol.}

See Special Issue Pattern Formation edited by Michael K. Richardson and Cheng-Ming Chuong at: http://www.ijdb.ehu.es/web/contents.php?vol=53\&issue=5-6

Expression of Shisa2, a modulator of both Wnt and Fgf signaling, in the chick embryo Thomas A. Hedge and Ivor Mason Int. J. Dev. Biol. (2008) 52: 81-85

Mouse-chick neural chimeras

Josiane Fontaine-Pérus and Yvonnick Chéraud

Int. J. Dev. Biol. (2005) 49: 349-353

Ventral vs. dorsal chick dermal progenitor specification Ingrid Fliniaux, Jean P Viallet and Danielle Dhouailly Int. J. Dev. Biol. (2004) 48: 103-106

Molecular mechanisms controlling dorsal dermis generation from the somitic dermomyotome

Isabel Olivera-Martinez, Jacques Thélu and Danielle Dhouailly

Int. J. Dev. Biol. (2004) 48: 93-101

Notch activity is required to maintain floorplate identity and to control neurogenesis in the chick hindbrain and spinal cord

Isabelle le Roux, Julian Lewis and David Ish-Horowicz

Int. J. Dev. Biol. (2003) 47: 263-272

Melanoma Cell Adhesion Molecule (MCAM) expression in the myogenic lineage during early chick embryonic development

Cristina Pujades, Borhane Guez-Guez and Dominique Dunon

Int. J. Dev. Biol. (2002) 46: 263-266

Orienting axon growth: spinal nerve segmentation and surround-repulsion

D Tannahill, J M Britto, M M Vermeren, K Ohta, G M Cook and R J Keynes Int. J. Dev. Biol. (2000) 44: 119-127

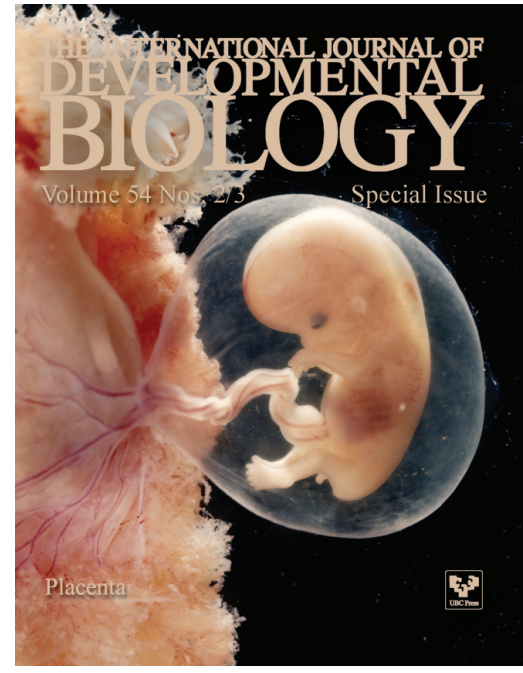

5 yr ISI Impact Factor $(2008)=3.271$

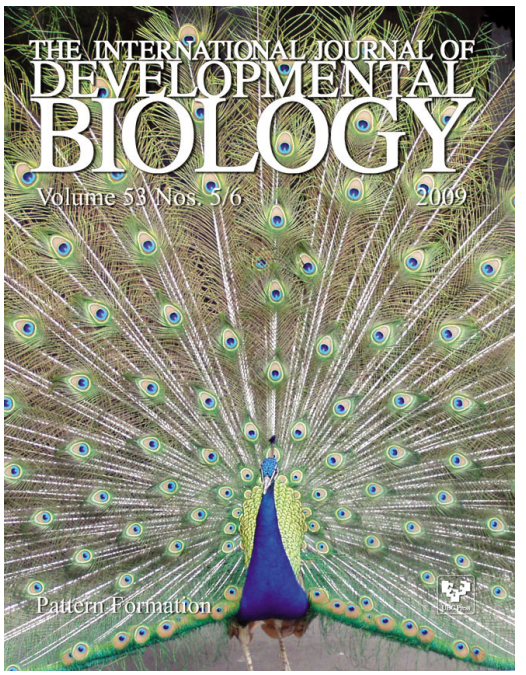

